\title{
Sensitivity to carbenicillin and ticarcillin, and the $\beta$-lactamases of Pseudomonas aeruginosa in the UK in 1978-79
}

\author{
JULIE D KING, T FARMER, C READING, AND R SUTHERLAND \\ From Beecham Pharmaceuticals Research Division, Chemotherapeutic Research Centre, Brockham Park, \\ Betchworth, Surrey, UK
}

SUMmaRY A total of 438 strains of Pseudomonas aeruginosa supplied by 10 hospitals in the UK reporting an increase in resistance to carbenicillin was tested for sensitivity to carbenicillin and ticarcillin. It was found that $85 \%$ of the strains were inhibited by $125 \mu \mathrm{g}$ carbenicillin $/ \mathrm{ml}$ and $87 \%$ by $50 \mu \mathrm{g}$ ticarcillin/ml, and that ticarcillin was from two- to four-fold more active than carbenicillin against the majority of these strains. Strains with a high level of resistance to carbenicillin (MIC $>1000 \mu \mathrm{g} / \mathrm{ml}$ ) possessed constitutive $\beta$-lactamases, and five different types of enzyme were identified. There was good correlation between minimum inhibitory concentrations and the results of disc sensitivity tests in this study, $82 \%$ with the $100 \mu \mathrm{g}$ carbenicillin disc and $90 \%$ with the $75 \mu \mathrm{g}$ ticarcillin disc, but results reported in the hospital laboratory tests with the carbenicillin disc were less satisfactory (64\% correlation). From a comparison with data reported in 1967 there does not appear to have been a significant increase in the incidence of carbenicillin-resistant strains of Ps aeruginosa in the UK.

The development of resistant strains of Pseudomonas aeruginosa during treatment with carbenicillin 1 and the emergence of strains with a high level of resistance $^{2}$ were reported relatively soon after the introduction of the broad-spectrum penicillin into clinical practice in 1967. Not long after, strains of $P$ s aeruginosa possessing chromosomal or plasmidmediated $\beta$-lactamases, which readily inactivated carbenicillin, were isolated, ${ }^{34}$ and concern was expressed regarding the possible rapid development of bacterial resistance to carbenicillin.

This report describes the results of tests to determine the sensitivity of strains of Ps aeruginosa isolated in 1978 and 1979 from 10 hospitals in the United Kingdom reporting an increase in the incidence of resistance to carbenicillin. The opportunity was also taken to measure the sensitivity of the organisms to ticarcillin ( $\alpha$-carboxy-3-thienylmethyl penicillin), an analogue of carbenicillin with improved antipseudomonas activity ${ }^{5}$ which became available in the UK in 1979.

Received for publication 18 September 1979

\section{Material and methods}

CULTURES

Eight hospitals in England, one in Scotland, and one in Wales each agreed to supply 50 consecutive strains of $P s$ aeruginosa isolated in the routine laboratory for inclusion in this study. A total of 438 cultures from a wide variety of clinical sources was received between October 1978 and February 1979.

\section{ANTIBIOTICS}

Carbenicillin and ticarcillin (disodium salts) were laboratory reference preparations (Beecham Pharmaceuticals). Antibiotic sensitivity discs containing carbenicillin $(100 \mu \mathrm{g})$ and ticarcillin $(75 \mu \mathrm{g})$ were commercial samples supplied by Mast Laboratories.

\section{MINIMUM INHIBITORY CONCENTRATIONS}

Serial dilutions of carbenicillin and ticarcillin were added to $18 \mathrm{ml}$ volumes of Blood Agar Base (Oxoid, CM55) in petri dishes. The plates were dried for 30 minutes at $55^{\circ}$ and inoculated with $0.001 \mathrm{ml}$ of a 
$1 / 50$ dilution of an overnight broth culture of the test organism by means of an inoculating device delivering 20 cultures to each plate. The final inoculum was approximately $10^{4}$ cells per drop, as recommended for the ICS method. ${ }^{6}$ The plates were incubated for 18 hours at $37^{\circ} \mathrm{C}$, and the minimum inhibitory concentrations were determined as the lowest concentrations preventing visible growth.

\section{ANTIBIOTIC DISC SENSITIVITY TESTS}

Antibiotic disc sensitivity tests were performed by the method described by the Association of Clinical Pathologists. ${ }^{7}$ Petri dishes $(90 \mathrm{~mm})$ containing Blood Agar Base to a depth of $4 \mathrm{~mm}$ were flooded with a 1/5000 dilution of an overnight broth culture of the test organism. The excess fluid was removed with a pasteur pipette, and the plates were dried at $37^{\circ} \mathrm{C}$ for 30 minutes. The antibiotic sensitivity discs were pressed firmly on the surface of the agar, and zones of inhibition were measured after 18 hours at $37^{\circ} \mathrm{C}$. Each test included the control strain, Ps aeruginosa NCTC 10662, and the sensitivity of the test cultures was interpreted by comparison with the control strain, as shown below:

Sensitive-zone diameter similar or larger than that of the control.

Moderately sensitive-zone diameter of at least $12 \mathrm{~mm}$ but reduced by more than $6 \mathrm{~mm}$ when compared with the control.

Resistant-zone diameter of $10 \mathrm{~mm}$ or less.

\section{$\beta$-LACTAMASES}

Ehrlenmeyer flasks $(500 \mathrm{ml})$ containing $100 \mathrm{ml}$ of a sterile tryptone medium (3.2\% tryptone (Oxoid), $2 \%$ yeast extract (Oxoid), and $0.5 \% \mathrm{NaCl}$ ) were inoculated with $1 \% \mathrm{v} / \mathrm{v}$ additions of overnight broth cultures (Oxoid No. 2) of the test organisms. For each of the cultures two flasks were inoculated and shaken at $30^{\circ} \mathrm{C}$ and $240 \mathrm{rpm}$. After 3.5 hours' incubation, 6-aminopenicillanic acid $(500 \mu \mathrm{g} / \mathrm{ml})$ was added to one of the flasks in order to induce $\beta$-lactamase production. After 7 hours' incubation the cells were collected by centrifugation at $22500 \mathrm{~g}$ for 15 minutes at $5^{\circ} \mathrm{C}$ and resuspended in $2.5 \mathrm{ml}$ of distilled water. These suspensions were ultrasonicated for 3 minutes (MSE ultrasonic disintegrator, MSE Scientific Instruments, Crawley, Sussex) using an ice bath to cool the samples. The cell debris was removed by centrifugation at $38000 \mathrm{~g}$ for 1 hour at $5^{\circ} \mathrm{C}$. The supernatants were examined for $\beta$-lactamase activity.

Isoelectric focusing of $\beta$-lactamases 8 was carried out using LKB Ampholine PAG plates (pH 3.5-9.5) and the LKB Multiphor system (LKB Instruments Ltd, Croydon). Focusing was carried out at $30 \mathrm{~W}$ and $1.4 \mathrm{kV}$ settings with an LKB 2103 power supply for 1.5 hours at $5^{\circ} \mathrm{C}$. Enzyme zones were visualised by overlaying with filter paper soaked in the chromogenic cephalosporin, nitrocefin $(500 \mu \mathrm{g} /$ $\mathrm{ml}$ ). The paper was left in contact with the gel, and the zones formed were observed by inverting the plate.

Substrate profiles were determined by measuring initial rates of substrate hydrolysis at $37^{\circ} \mathrm{C}$ in $0.05 \mathrm{~m}$ sodium phosphate buffer, pH 7.3. Using a spectrophotometric assay, ${ }^{9}$ rates of hydrolysis of the test penicillins were determined at a concentration of $500 \mu \mathrm{g}$ substrate $/ \mathrm{ml}$ and at $240 \mathrm{~nm}$ for ampicillin, benzylpenicillin, and carbenicillin, and $263 \mathrm{~nm}$ for oxacillin. Hydrolysis of cephaloridine $(250 \mu \mathrm{g} / \mathrm{ml})$ was followed by measuring the loss of absorbance at $290 \mathrm{~nm}$.

\section{Results}

MINIMUM INHIBITORY CONCENTRATIONS The distribution of the minimum inhibitory concentrations of carbenicillin and ticarcillin against 438 isolates of Ps aeruginosa is illustrated in Table 1, which shows the cumulative percentage strains inhibited by the compounds. For comparison, the table also includes corresponding data reported for carbenicillin in $1967^{10}$ and for ticarcillin in 1970.5 Most strains were inhibited by concentrations readily achievable with recommended doses of the compounds. For instance, $85 \%$ of the strains were inhibited by $125 \mu \mathrm{g}$ carbenicillin/ml and $87 \%$ by $50 \mu \mathrm{g}$ ticarcillin $/ \mathrm{ml}$. Ticarcillin was twice as active as carbenicillin against half of the strains tested and four-fold more active against one-third of the strains (Table 2). In general, strains with a high level of

Table 1 Sensitivity of Pseudomonas aeruginosa to carbenicillin and ticarcillin

\begin{tabular}{|c|c|c|c|c|c|c|c|c|c|c|c|c|c|}
\hline \multirow[t]{2}{*}{ Antibiotic } & \multirow{2}{*}{$\begin{array}{l}\text { Date of } \\
\text { study }\end{array}$} & \multirow{2}{*}{$\begin{array}{l}\text { No. of } \\
\text { strains }\end{array}$} & \multicolumn{11}{|c|}{ Cumulative $\%$ strains inhibited by $(\mu \mathrm{g} / \mathrm{ml})$} \\
\hline & & & $\leqslant 1 \cdot 0$ & $2 \cdot 5$ & $5 \cdot 0$ & 10 & 25 & 50 & 125 & 250 & 500 & 1000 & $>1000$ \\
\hline
\end{tabular}

*Reference 10.

†Reference 5. 
Table 2 Relative activities of carbenicillin and ticarcillin against 438 strains of Pseudomonas aeruginosa

\begin{tabular}{lllrrr}
\hline & \multicolumn{5}{l}{$\begin{array}{l}\text {-fold increase in activity of ticarcillin } \\
\text { compared }\end{array}$} \\
\cline { 2 - 6 } & 0.5 & 1 & 2 & 4 & 8 \\
\hline No. of strains & \multicolumn{1}{l}{ carbenicillin* } \\
$\%$ & 8 & 48 & 214 & 155 & 13 \\
\hline & 2 & 11 & 49 & 35 & 3 \\
\hline
\end{tabular}

*Calculated from $\frac{\text { Carbenicillin MIC }}{\text { Ticarcillin MIC }}$ for each strain.

resistance to carbenicillin (MIC $>1000 \mu \mathrm{g} / \mathrm{ml}$ ) were equally resistant also to ticarcillin.

A comparison of MIC values of the penicillins against the current isolates with those reported originally for the compounds shows that there had been only a relatively small increase in the incidence of resistant strains (Table 1). Thus, in $1967,7 \%$ of the strains tested were not inhibited by $125 \mu \mathrm{g}$ carbenicillin/ml, while in $1978 / 7915 \%$ of the strains were resistant to this concentration of carbenicillin. However, although the incidence of resistance was relatively unaltered, there was a change in that in 1967 all strains were inhibited by $250 \mu \mathrm{g}$ carbenicillin/ $\mathrm{ml}$, whereas $6 \%$ of the current isolates were not sensitive to this concentration and $3 \%$ of the total were resistant to $1000 \mu \mathrm{g}$ carbenicillin $/ \mathrm{ml}$. Biochemical studies revealed that the strains with a high level of resistance (MIC $>1000 \mu \mathrm{g} / \mathrm{ml}$ ) possessed $\beta$-lactamases capable of destroying carbenicillin and ticarcillin (see below).

Although the overall incidence of resistance to carbenicillin $(15 \%)$ and ticarcillin $(13 \%)$ remained low there was considerable variation in the proportion of resistant strains in the individual hospitals (Table 3). In most cases the incidence of resistance
Table 3 Distribution of sensitive strains of Pseudomonas aeruginosa

\begin{tabular}{llll}
\hline Hospital & \multirow{2}{*}{$\begin{array}{l}\text { No. of strains } \\
\text { tested }\end{array}$} & \multicolumn{2}{c}{$\%$ Strains inhibited by } \\
\cline { 3 - 4 } & & $\begin{array}{l}\text { Carbenicillin } \\
125 \mu \mathrm{g} / \mathrm{ml}\end{array}$ & $\begin{array}{c}\text { Ticarcillin } \\
50 \mu \mathrm{g} / \mathrm{ml}\end{array}$ \\
\hline 1 & 32 & 100 & 100 \\
2 & 43 & 81 & 84 \\
3 & 49 & 61 & 61 \\
4 & 47 & 89 & 87 \\
5 & 18 & 100 & 100 \\
6 & 53 & 89 & 91 \\
7 & 50 & 78 & 76 \\
8 & 50 & 98 & 98 \\
9 & 56 & 84 & 89 \\
10 & 40 & 88 & 95 \\
Total & 438 & 85 & 87 \\
\hline
\end{tabular}

lay between $10 \%$ and $20 \%$ of isolates, but in hospital 3 two-fifths of the strains were relatively insensitive to the penicillins. On the other hand, in two of the hospitals (1 and 5) all isolates tested were sensitive to carbenicillin and ticarcillin.

\section{DISC SENSITIVITY TESTS}

Data in Table 4 show the correlation between MIC values and the results of the antibiotic disc sensitivity tests. Overall, there was relatively good correlation between the results of the disc tests carried out in this study and the MIC values. With carbenicillin, $82 \%$ of the 365 strains sensitive to $125 \mu \mathrm{g}$ carbenicilin/ml were classified as being sensitive to the $100 \mu \mathrm{g}$ carbenicillin disc, and the remainder (save one strain) were classified as being moderately sensitive to the carbenicillin disc. The performance of the ticarcillin disc was slightly better in that $90 \%$ of the 372 strains inhibited by $50 \mu \mathrm{g}$ ticarcillin/ml were considered to be sensitive to

Table 4 Correlation between results of serial-dilution (MIC) tests and antibiotic disc sensitivity tests

\begin{tabular}{|c|c|c|c|c|c|c|c|c|}
\hline \multirow[t]{4}{*}{ Hospital } & \multicolumn{8}{|c|}{ Number of strains } \\
\hline & \multicolumn{4}{|l|}{ Carbenicillin } & \multicolumn{4}{|l|}{ Ticarcillin } \\
\hline & \multirow{2}{*}{$\begin{array}{l}M I C \\
\leqslant 125 \mu \mathrm{g} / \mathrm{ml}\end{array}$} & \multicolumn{3}{|c|}{$100 \mu \mathrm{g}$ disc } & \multirow{2}{*}{$\begin{array}{l}M I C \\
\leqslant 50 \mu \mathrm{g} / \mathrm{ml}\end{array}$} & \multicolumn{3}{|c|}{$75 \mu g$ disc } \\
\hline & & $S$ & $M S$ & $\boldsymbol{R}$ & & $S$ & $M S$ & $\boldsymbol{R}$ \\
\hline 1 & 31 & 20 & 11 & 0 & 32 & 29 & 3 & 0 \\
\hline 2 & 34 & $25(22)^{*}$ & 9 & 0 & 35 & 31 & 4 & 0 \\
\hline 3 & 29 & $27(21)$ & 2 & 0 & 29 & 26 & 3 & 0 \\
\hline$\ddot{4}$ & 39 & 28 (29) & 11 & 0 & 38 & 35 & 3 & 0 \\
\hline 5 & 16 & 13 (13) & 3 & 0 & 16 & 13 & 3 & 0 \\
\hline 6 & 46 & 42 (3) & 4 & 0 & 47 & 46 & 1 & 0 \\
\hline 7 & 39 & $36(32)$ & 3 & $\mathbf{0}$ & 38 & 36 & 2 & 0 \\
\hline 8 & 49 & $35(40)$ & 13 & 1 & 49 & 42 & 7 & 0 \\
\hline 9 & 47 & $44(30)$ & 3 & 0 & 50 & 44 & 6 & 0 \\
\hline 10 & 35 & $31-$ & 4 & 0 & 38 & 31 & 7 & 0 \\
\hline Total & 365 & $\begin{array}{l}301 \\
(82 \%)(6\end{array}$ & 63 & 1 & 372 & $\begin{array}{l}333 \\
(90 \%)\end{array}$ & 39 & $\mathbf{0}$ \\
\hline
\end{tabular}

* Number of strains reported sensitive by hospital laboratory. 
the $75 \mu \mathrm{g}$ ticarcillin disc, the remaining $10 \%$ being classified as moderately sensitive. The results of the disc sensitivity tests reported by eight hospital laboratories showed that 190 of 253 strains inhibited by $125 \mu \mathrm{g}$ carbenicillin $/ \mathrm{ml}$ were reported to be sensitive to the $100 \mu \mathrm{g}$ carbenicillin disc, an overall correlation of $64 \%$ correct results. There was considerable variation among the laboratories, ranging from $7 \%$ to $82 \%$ correlation between the disc tests and MIC values (Table 4).

\section{$\beta$-LACTAMASES}

The $\beta$-lactamases produced by 17 carbenicillinresistant isolates (MIC $>125 \mu \mathrm{g} / \mathrm{ml}$ ) are shown in Table 5. Identification was based upon Iso-Electric Focusing (IEF) characteristics and by substrateprofile data. ${ }^{8}$ All organisms (except strain 13) produced an inducible enzyme with a high isoelectric point (pI 7.9-8.8) and the six strains possessing this enzyme solely gave substrate profiles corresponding to that obtained with the Sabath type $\beta$-lactamase. The rest of the strains produced a variety of constitutive $\beta$-lactamases which were identified tentatively as the Dalgleish enzyme, TEM 1 , the isoxazolyl-hydrolysing enzymes OXA 1 and OXA 2, and enzymes in strains 9,10 , and 11 which might have been either RMS 13911 or RPL 11,12 as these latter have identical pIs (5.7) and similar substrate profiles. The six strains producing the Sabath $\beta$-lactamase exclusively were usually less resistant to carbenicillin (MlC $250-1000 \mu \mathrm{g} / \mathrm{ml}$ ) than the strains that also possessed constitutive $\beta$ lactamases (MIC > $1000 \mu \mathrm{g} / \mathrm{ml}$ ).

\section{Discussion}

In an early publication on carbenicillin from this laboratory, it was reported that $94 \%$ of 206 strains of $P$ s aeruginosa isolated in the UK in 1967 were inhibited by $125 \mu \mathrm{g}$ carbenicillin $/ \mathrm{ml} .^{10}$ The results reported here show an apparent slight reduction in the incidence of sensitivity, $85 \%$ of the 438 strains of Ps aeruginosa tested being inhibited by $125 \mu \mathrm{g}$ carbenicillin $/ \mathrm{ml}$, but there appears to have been no great increase overall in the incidence of carbenicillinresistant strains of Ps aeruginosa in the UK since the introduction of the compound in 1967. This finding is in agreement with the results of a recent survey in four hospitals in the United States where $86 \%$ of 718 isolates of $P s$ aeruginosa were reported to be sensitive to $128 \mu \mathrm{g}$ carbenicillin $/ \mathrm{ml} .{ }^{13}$ However, there was considerable variation from hospital to hospital, ranging from $39 \%$ of strains resistant in one hospital to $100 \%$ sensitivity in two hospitals, which may reflect the volume of usage and type of patient or infection treated.

The isolation of strains with high-level resistance to carbenicillin and possessing constitutive $\beta$ lactamases capable of inactivating the compound, in addition to the Sabath enzyme typical of this organism, ${ }^{8}$ was reported in $1970^{3}{ }^{4}$ but only one-fifth of the carbenicillin-resistant strains studied here were found to have enzymes of this type. The majority of strains classified as being resistant showed MIC values of $250-1000 \mu \mathrm{g}$ carbenicillin $/ \mathrm{ml}$ and possessed only the inducible Sabath enzyme, against which carbenicillin is relatively stable. In view of the small numbers of resistant strains isolated, demonstration of the presence of five different constitutive $\beta$-lactamases in the 17 strains studied is unexpected. The pattern of distribution appears to suggest that a single enzyme type predominated in the hospital of isolation but the numbers involved are very small.

Table $5 \quad \beta$-Lactamases produced by carbenicillin-resistant isolates of Pseudomonas aeruginosa

\begin{tabular}{|c|c|c|c|c|c|c|}
\hline \multirow[t]{2}{*}{ Hospital } & \multirow[t]{2}{*}{ Strain no. } & \multirow[t]{2}{*}{$\begin{array}{l}\text { Carbenicillin } M I C \\
(\mu g / m l)\end{array}$} & \multicolumn{2}{|c|}{$\begin{array}{l}\text { Main band isoelectric } \\
\text { point }(p I)\end{array}$} & \multicolumn{2}{|c|}{ Probable $\beta$-lactamase } \\
\hline & & & 1 & 2 & 1 & 2 \\
\hline \multirow{3}{*}{2} & 1 & $>1000$ & $8 \cdot 0$ & $5 \cdot 1$ & Sabath & Dalgleish \\
\hline & 2 & $>1000$ & $8 \cdot 0$ & $5 \cdot 1$ & Sabath & Dalgleish \\
\hline & 3 & $>1000$ & $8 \cdot 0$ & $5 \cdot 1$ & Sabath & Dalgleish \\
\hline \multirow{3}{*}{3} & 4 & 1000 & $8 \cdot 0$ & - & Sabath & - \\
\hline & 5 & 1000 & $8 \cdot 5$ & -- & Sabath & - \\
\hline & 6 & 1000 & $8 \cdot 5$ & - & Sabath & - \\
\hline 4 & 7 & $>1000$ & $8 \cdot 8$ & $5 \cdot 4$ & Sabath & TEM 1 \\
\hline \multirow[t]{3}{*}{6} & 8 & 250 & $8 \cdot 0$ & - & Sabath & - \\
\hline & 9 & $>1000$ & $8 \cdot 2$ & $5 \cdot 7$ & Sabath & RMS 139 \\
\hline & 10 & $>1000$ & $8 \cdot 1$ & $5 \cdot 8$ & Sabath & or \\
\hline \multirow[t]{3}{*}{7} & 11 & $>1000$ & $8 \cdot 1$ & $5 \cdot 8$ & Sabath & RPL 11 \\
\hline & 12 & 500 & $8 \cdot 0$ & $7 \cdot 4$ & Sabath & OXA 1 \\
\hline & 13 & $>1000$ & - & $5 \cdot 4$ & - & TEM 1 \\
\hline \multirow{2}{*}{9} & 14 & $>1000$ & $8 \cdot 6$ & - & Sabath & - \\
\hline & 15 & $>1000$ & $8 \cdot 4$ & $8 \cdot 1$ & Sabath & OXA 2 \\
\hline \multirow[t]{2}{*}{10} & 16 & $>1000$ & $8 \cdot 4$ & $8 \cdot 1$ & Sabath & OXA 2 \\
\hline & 17 & 250 & $8 \cdot 5$ & - & Sabath & - \\
\hline
\end{tabular}


It is of interest that the cultures tested here were supplied by 10 hospitals thought to have experienced an increase in the incidence of carbenicillin-resistant isolates of Ps aeruginosa, although in fact the overall level of resistance was found not to be high, being no more than $10-20 \%$ of the strains supplied by the majority of hospitals. It may be that the batches of isolates tested were unrepresentative, but it could also be that there are problems in sensitivity testing, as is evidenced by the fact that only $64 \%$ of the strains inhibited by $125 \mu \mathrm{g}$ carbenicillin $/ \mathrm{ml}$ were classified as being sensitive to carbenicillin on the basis of hospital disc sensitivity tests. There are difficulties in testing the sensitivity of Ps aeruginosa to carbenicillin as carbenicillin sensitivity discs are relatively unstable and readily inactivated unless the correct storage conditions are used, ${ }^{14}$ and a large inoculum yields small inhibition zones, possibly with apparently resistant colonies. ${ }^{15}$ Another factor that may contribute is that Psaeruginosa NCTC 10662, the control strain recommended in the UK, may be more sensitive to carbenicillin than are many isolates that may be considered clinically sensitive (MIC $\leqslant 125 \mu \mathrm{g} / \mathrm{ml}$ ). For instance, the culture of Ps aeruginosa NCTC 10662 used in this study was inhibited in eight out of 10 tests by $25 \mu \mathrm{g}$ carbenicillin/ml, and consequently a number of strains with MIC values of $50-125 \mu \mathrm{g}$ carbenicillin $/ \mathrm{ml}$ were classified as being only moderately sensitive.

The opportunity was also taken in this study to test these recent clinical isolates for sensitivity to ticarcillin, and the results of the tests confirmed that ticarcillin was two to four times more active than carbenicillin against the majority of strains tested. ${ }^{5}$ Strains with an increased level of resistance to carbenicillin usually showed a similar increase in resistance to ticarcillin, and those strains with a high level of resistance to carbenicillin were equally resistant to ticarcillin. In the disc sensitivity tests, there was rather better correlation between minimum inhibitory concentrations and the results of the disc tests with the $75 \mu \mathrm{g}$ ticarcillin disc than with the $100 \mu \mathrm{g}$ carbenicillin disc, in keeping with reports from the USA. ${ }^{16} 17$

\section{References}

1 Darrell JH, Waterworth PM. Carbenicillin resistance in Pseudomonas aeruginosa from clinical material. Br Med J 1969;3:141-3.

${ }^{2}$ Lowbury EJL, Kidson A, Lilly HA, Ayliffe GAJ, Jones RJ. Sensitivity of Pseudomonas aeruginosa to antibiotics: emergence of strains highly resistant to carbenicillin. Lancet 1969;2:448-52.

${ }^{3}$ Newsom SWB, Sykes RB, Richmond MH. Detection of a $\beta$-lactamase markedly active against carbenicillin in a strain of Pseudomonas aeruginosa. J Bacteriol 1970;101:1079-80.

${ }^{4}$ Fullbrook PD, Elson SW, Slocombe B. R-factor mediated $\beta$-lactamase in Pseudomonas aeruginosa. Nature 1970;226:1054-6.

${ }^{5}$ Sutherland R, Burnett J, Rolinson GN. a-Carboxy-3thienyl-methylpenicillin (BRL 2288), a new semisynthetic penicillin: in vitro evaluation. Antimicrob Agents Chemother 1970. $1971: 390-5$.

${ }^{6}$ Ericsson HM, Sherris JC. Antibiotic sensitivity testing. Report of an international collaborative study. Acta Pathol Microbiol Scand 1971;217 (Suppl).

${ }^{7}$ Stokes EJ, Waterworth PM. Antibiotic sensitivity tests by diffusion methods. Association of Clinical Pathologists, Broadsheet 55. 1972.

${ }^{8}$ Sykes RB, Matthew M. The $\beta$-lactamases of Gramnegative bacteria and their role in resistance to $\beta$-lactam antibiotics. J Antimicrob Chemother 1976; 2:115-57.

${ }^{9}$ Samuni A. A direct spectrophotometric assay and determination of Michaelis constants for the $\beta$ lactamase reaction. Anal Biochem 1975;63:17-26.

10 Rolinson GN, Sutherland R. Carbenicillin, a new semisynthetic penicillin active against Pseudomonas aeruginosa. Antimicrob Agents Chemother 1967. 1968:609-13.

${ }^{11}$ Sawada Y, Yaginuma S, Tai M, Iyobe S, Mitsuhashi S. Plasmid-mediated penicillin beta-lactamases in Pseudomonas aeruginosa. Antimicrob Agents Chemother 1976;9:55-60.

12 Matthew M,Sykes RB. Properties of the beta-lactamase specified by the Pseudomonas plasmid RPL 11. $J$ Bacteriol 1977;132:341-5.

13 Fuchs PC, Gavan TL, Gerlach EH, Jones RN, Barry AL, Thornsberry C. Ticarcillin: a collaborative in vitro comparison with carbenicillin against over 9,000 clinical bacterial isolates. Am J Med Sc 1977; 274:255-63.

14 Griffith LJ. Pseudomonas resistance due to inactivated susceptibility discs. Antimicrob Agents Chemother 1973;4:646-7.

15 Knudsen ET, Rolinson GN, Sutherland R. Carbenicillin: a new semisynthetic penicillin active against Pseudomonas pyocyanea. Br Med J 1967;3: 75-8.

16 Parry MF, Neu HC. Comparison and evaluation of ticarcillin and carbenicillin using disc diffusion methods. Antimicrob Agents Chemother 1976;9: 625-32.

17 Fuchs PC, Thornsberry C, Barry AL, Gavan TL, Gerlach EH, Jones RN. Ticarcillin, carbenicillin and BL-P1908: in vitro comparison of three antipseudomonal semisynthetic penicillins. $J$ Antibiot 1977;30:1098-1106.

Requests for reprints to: Dr $\mathbf{R}$ Sutherland, Beecham Pharmaceuticals Research Division, Chemotherapeutic Research Centre, Brockham Park, Betchworth, Surrey, UK. 